\title{
UNDERSTANDING SCHOLARLY PRESUPPOSITIONS: A CRUCIAL TOOL FOR RESEARCH?*
}

\author{
Paul Helm
}

\section{Summary}

It is argued that all scholarly enquiry unavoidably rests on either tacitly or explicitly accepted presuppositions. Such presuppositions control enquiry with varying degrees of strength, functioning either as axioms or methodological assumptions. In the interests of objectivity the Christian scholar has the duty to test his own presuppositions by reference to the primary documents of his faith, and by reflecting upon the different presuppositions adopted by other scholars. The quest for scholarly objectivity must not be confused with neutrality.

One sometimes hears it said that it is possible to undertake biblical exegesis 'scientifically', without presuppositions; or, contrariwise, that differences between scholars boil down to differences in their presuppositions, the implication of the remark being that if the disagreement is about presuppositions then at that point argument must cease. Sometimes 'presuppositionalism' is elevated into a method of Christian apologetics; only if the Bible is presupposed, it is said, can life be made sense of.

Thus may presuppositions or their absence be praised or blamed. In view of the widespread and differing uses of the term it may be worthwhile to reflect about presuppositions in a little more consecutive fashion than is usually done. It is intended (I) to begin with five theses about presuppositions, each briefly defended, (II) to illustrate some of these by reference to the study of the text of Scripture and (III) to conclude from these reflections with some brief remarks about objectivity and neutrality.

\section{Five Theses about Presuppositions}

\section{All argument or rational enquiry requires Presuppositions}

There is nothing in the least surprising about this. Conclusions cannot be spun out of fresh air, but need support. And that

* Based on a graduate seminar given at Tyndale House, 12 November 1992. 
support begins with premisses, propositions which are taken for granted in the enquiry. The need for such premisses is a matter of logic. In order to conduct an enquiry some things must be taken for granted. If everything were to be questioned at once then, paradoxically, nothing could be questioned. It is only by holding certain things constant that certain other things can be varied. What is held constant on one occasion may, on another occasion, be called into question and critically examined. But this can only happen if yet other matters are taken as premisses or presuppositions.

This is most obviously the case in deductive argument, the purest kind of 'reason'. Deduction is a way of validly moving from one proposition or set of propositions to another, the conclusion. Valid deduction preserves truth; it does not create it. It preserves truth by deducing one proposition from another, or from a set of propositions. So there is no such thing as a conclusion that is not derived from a premise. If I know that (or take it for granted that) all bees sting, and that Josephine is a bee, then it follows that Josephine stings. What I take for granted in this argument are the premisses, or (if you like) the presuppositions. These premisses may in turn be derived from other premisses or presuppositions (I shall discuss this point later) but they cannot be regarded as conclusions at the same time that they are functioning as premisses. For if they are questioned then this questioning takes place in the light of other propositions which are functioning as premisses.

But premisses or presuppositions do not only occur in deductive argument. They function crucially in the less formal kinds of intellectual enquiry. We investigate a part of our world, a text say, in the light of certain things we take for granted about that text. These may be various; what we think is obviously true, or the assured results of earlier enquiries, or we may, in a more tentative vein, assume or accept a hypothesis about the text which we wish to test.

The thought that we might conduct rational enquiry in a premise-free way is surely incoherent, just as it is incoherent to suppose that we could conduct enquiries without having some problem or project in view.

For this reason it is always appropriate to examine and to reflect upon either one's own, or others' premisses. Such an 
examination may reveal presuppositions which are 'neutral' in the sense that they are accepted by everyone, or by nearly everyone; or they may be premisses which are unquestioned within one cultural group, but which are highly contentious elsewhere.

\section{Premisses (or presuppositions) are unavoidable}

The economists quite correctly say that there is no such thing as a free lunch. Our previous discussion underlines the fact that there is no such thing as a free conclusion either. Conclusions pay a price, not the price of a lunch, but the intellectual price of accepting the premise or premisses which either entail or in some other way make reasonable the acceptance of the conclusion. Some premisses may be so obvious to most of us that we may even find it hard to identify them, but they are genuine premisses for all that, and as such they pay a price, though it may be one that we are all willing to pay without thinking too much about it. But other premisses may be more contentious.

\section{Not all premisses are presuppositions}

We have stressed that any argument or investigation about anything must begin somewhere, with premisses taken for granted. What is taken for granted may be really assumed, as part of the bona fide belief of the arguer or investigator, or it may be assumed for methodological reasons. One may make certain assumptions, and use these as premisses, without really believing them. One reason for doing this may simply be that it is more convenient to do so. So one might make the assumption that religion can be explained as the result of a natural human religiosity, that there is no place in religion for divine revelation. Doing this might throw into relief certain characteristics of all religion. But here one is simply resolving to treat religion in this way, and adopting this method is perfectly consistent with believing that at least one religion cannot be fully explained without recourse to the idea of special divine revelation.

What makes a premise into a real, as opposed to a mere, methodological presupposition? I suggest the following two or three features. Firstly, premisses become presuppositions when they are not merely of local importance, but concern an entire field of study, and even an entire approach to all data. This is one of the reasons why presuppositions are of interest to the philosopher, because being so general and basic, they are 
often philosophical in character, perhaps without the one who holds them realising the fact.

Thus there may be presuppositions that are metaphysical in character. For example, principles about the human person; that a person is a soul, or a machine, or a psycho-somatic unity. Or about God (that he exists or does not exist); that he is capable of intervening in history; that he is the most perfect being; that he is limited in power. Or about history; that no period of history is of more religious significance than any other; that no historical event can be predicted.

There can be presuppositions about our knowledge; for instance, that nothing in religion can be a mystery; that no claims about revelation in history can be established with certainty; or that no truths about the past are normative for present belief; that testimony to the occurrence of miracles is always unreliable.

There can also be presuppositions about values; that God could never command human sacrifice; that every moral claim must be assessed by the conscience; or that prophets are morally superior to priests.

So premisses which function as presuppositions have at least some of the properties of axioms. They are basic, and central; other truths can be derived from them; and it may even be claimed that certain presuppositions are obvious, or universally accepted ('no educated person would claim that...') or even that they are self-evidently true.

In the second place, and connected with their generality, presuppositions are a matter of commitment. Once they cease to function as presuppositions they can be revised, abandoned, or adopted (as we shall see later). But insofar as they maintain their place as presuppositions they are unrevisable.

But finally, what makes a principle into a presupposition is that it exercises control over an enquiry. ${ }^{1}$ If something is a presupposition then obviously nothing could be admitted as the conclusion of an inquiry that is inconsistent with the presupposition. If it is a presupposition of enquiry that, for example, no truths about the past are normative for present belief then it is not possible, consistently with that, to conclude

\footnotetext{
1For an illuminating discussion of the control which religion may exercise over rational enquiry, see Nicholas Wolterstorff, Reason Within the Bounds of Religion (Grand Rapids, Eerdmans 1984) 2nd ed.
} 
that there is a period in the past when God revealed himself in a special manner.

\section{Presuppositions come in different strengths}

We have noted that presuppositions control enquiry. But they can exercise this control with different degrees of strength. The least degree is, as we saw a moment ago, when they act as necessary controls over conclusions, ruling out certain conclusions as inconsistent with the presuppositions. But they can act more strongly when, for example, presuppositions require or necessitate certain conclusions.

They can be stronger even than this, though this may be hard to imagine. For so far we have been considering the control that presuppositions exercise solely in terms of their truth. But it is possible to maintain not merely that, say, any conclusion must be consistent with a presupposition, but that the meaning of any conclusion must be obtained from some presupposition.

This hyper-strong form of presuppositionalism can be illustrated as follows. As noted at the beginning, presuppositionalism is the name of a family of religious apologetic strategies. One form is as follows: it is only by presupposing the Bible when understood in such a way (i.e. as having a certain meaning) that it is possible to make sense of the meaning of anything else. This is a presuppositionalism not only of truth but of meaning as well, since it requires one to presuppose, to assume, to take as axiomatic, all the expressions of the Bible with a certain meaning. For obviously if or to the extent that the meaning of the Bible is unclear or contentious then it cannot function as a presupposition. If its meaning is unclear, how could the claim that the meaning of everything else depends upon the meaning of the Bible have any apologetic force or attraction? For the unclarity in the meaning of some of the texts of Scripture would simply be transmitted to the conclusion. Either that, or only part of the Bible, that part the meaning of which was clear or undisputed, could function presuppositionally.

\section{Presuppositions must be distinguished from motives or drives}

We have seen that presuppositions are propositions ranging over whole fields of enquiry which may be accepted as basic, or axiomatic, and which to a greater or lesser degree control 
further enquiry. However, not everything that is basic in the sense that everything else depends upon it is a presupposition in our sense. A person may have a basic drive or centre of motivation. He may have an insatiable curiosity about the Dead Sea, say. Or he may have an ambition to write a commentary on every book of the New Testament. These may be the controlling drives or motives of his entire life. Such interests or ambitions may lead him into a particular field of study; they may sustain a person's intellectual effort over many years.

But they are not presuppositions in the sense in which we are using that term here. Such basic forces are powerful, but they are merely causal. From them alone nothing follows about the beliefs that a person will come to form about the Dead Sea or the books of the New Testament, though of course there may be an intertwining of basic drives in this causal sense, and presuppositions in the sense in which we have been discussing them.

\section{Presuppositions and Biblical Study}

It may be helpful if an attempt is made to earth what has so far been a rather abstract discussion of presuppositions in one field of enquiry. The examples that I shall use in what follows are purely illustrative, and so nothing substantive is meant to follow from them, one way or the other. The aim is to show how presuppositions may operate.

Suppose that someone claims that

(1) All that we can possibly be certain of are beliefs and experiences of some early followers of Jesus.

Suppose that he takes this not as a hypothesis to be tested, and not merely as the conclusion of some previous enquiry, but as a presupposition of enquiry about the nature of Jesus' ministry (say). How does this control further enquiry? Does it, for example, rule out

(2) We know no direct speech of Jesus himself.

Clearly not. To conclude this we would first need to be sure of

(3) None of the beliefs and experiences of the early followers of Jesus contain accurate records of his speech.

Suppose it is held, on the basis of our presupposition that 
(4) We know that the expressions of concrete meetings with the resurrected Jesus are literalised versions of resurrection visions.

Not only does this not follow from (1), it is actually inconsistent with (1). Or at least, it requires another premise beside (1) in order for it to be warranted. A premise such as

(5) It is plausible to interpret some of the beliefs and experiences of some early followers of Jesus as literalised versions of resurrection visions.

Some morals follow from how such a presupposition may and may not function. Paradoxically, perhaps, the vaguer and more general a person's basic presuppositions, the harder it is for them to yield any precise conclusions without help from a number of auxiliary premisses, premisses such as (5). Secondly, even if the main presupposition such as (1) is plausible, even compelling, the auxiliary hypothesis (5) may not be. Perhaps (1) is compelling, or certainly very plausible-for what it says is that as far as we know Jesus did not himself write anything, and this is widely accepted. But (5) is far from compelling. And any attempt to make it compelling is likely to make matters worse. For example, in order to make it compelling someone might claim

(6) The early followers of great religious leaders frequently turn their visions of the leader into literal happenings.

(6) might make (5) plausible, though it does not entail (5). But (6) does not look obviously true. In other words, for (6) to carry general conviction it looks as if it will have to be argued for; that is, derived from propositions more basic than itself, thus driving us back to presuppositions of greater generality and vagueness.

We referred a little earlier to the compellingness (or otherwise) of a presupposition. This, or something slightly weaker, such as extreme plausibility, is going to be needed if one person is going to share or adopt or retain the presupposition of another. We shall return to this point in the last section, when dealing with objectivity.

Let us try another epistemological presupposition, this time expressed in the form of a conditional;

(7) If one error has been detected in a narrative then all the remainder of the narrative is subject to dispute. 
Someone might use (7) as a presupposition, and combine it with

(8) An error has been detected in the text of Scripture

to conclude

(9) All of the text of Scripture (or all of some part of the text of Scripture) is subject to dispute.

This looks serious. But let us think again about (7). (7) is a hard saying. For consider (7a)

(7a) If one error has been detected in the telephone directory then all the other entries in the directory are subject to dispute.

The implausibility of (7a) makes it clear that (7) may express not so much judicious caution as positive paranoia. Because someone makes one mistake it does not (as a matter of logic) follow that everything he does and says is mistaken. In that direction lies complete scepticism.

Of course the phrase 'subject to dispute' is rather vague. It may simply be calling attention to the need for caution and sobriety, a warning against excessive credulity. But alternatively it may be claiming that if one error has been detected in the directory no other entries can ever be trusted. And this would seem to be an excessive and unwarranted conclusion to draw.

We have tried to show two main things so far. First, the characteristics of presuppositions, and the fact that we all have them. None of us can weave conclusions out of thin air or a cognitive vacuum, and insofar as we claim to draw scholarly conclusions from any area of enquiry we can do so only because we accept (tacitly or explicitly) one or more presuppositions, propositions which are basic to our particular enquiry, unrevisable in the enquiry, and which in some sense exert control over the results of the enquiry.

\section{Objectivity and Neutrality}

Each person who is engaged in research is concerned to minimise the number of false beliefs that he and his co-workers in the field hold, and to maximise the number of true beliefs. (This also is a presupposition, but it is taken for granted that the reader agrees with it). In this endeavour, presuppositions are inevitable, even vital, as we have seen. 
For not only do researchers wish to record data, they wish to organise it in answer to problems or in furtherance of some hypothesis. And each of us stands upon the shoulders of other workers in our field, inheriting their findings and with those findings, at least some of the presuppositions which validate them. How can we prevent our presuppositions from being mere prejudices, from pandering to our own subjective preferences and desires rather than conforming to the truth, from leading us away from the truth rather than ever nearer to it?

For anyone who takes a relativist or subjectivist view of truth such questions are not at all serious. But one thing that unites Christian enquirers (presumably) is the conviction that there is such a thing as objective truth; namely, whatever God has ordained (or permitted). So for them the question about presuppositions and objectivity is a rather pressing one. Does not the stress we have been laying upon presuppositions mean that any 'objective' enquiry is out of the question? Are we not all, with the best will in the world, held captive to our presuppositions?

Sometimes one encounters the following kind of argument:

(10) It is impossible to get back to 'pure objective truth' which is free from the subjectivity of personal experience and interpretation.

Therefore,

(11) We should not try to get back to objective historical truth, since it is impossible to do so.

But why does this follow? Why does it follow that because something is impossible to achieve we should not try to get as near to achieving it as we can? If you were a defendant in court, convinced of your innocence, it would hardly be a comfort to be told by the judge that since it is impossible to achieve 'perfect justice' the court would make no effort at all to establish the facts of the case. While pure truth and pure justice may be for us unattainable abstractions, there might be considerable advantages, perhaps even a duty, to strive to get as close to the truth as possible. And carrying out such a duty requires that every legitimate effort be made to get at the truth regarding innocence or guilt, and that such efforts do not include, say, tea-leaf reading. 
But how is it possible to make every effort to get at the objective truth, in the light of what we have learned about presuppositions? Do not the existence and the inevitability of presuppositions make striving for the objective truth a nonsense? For is not 'the truth' simply dictated by one's presuppositions? Is not all argument and all enquiry ultimately circular?

No. Because one has presuppositions it does not necessarily mean that they dictate one's conclusions. They may, if one is a presuppositionalist in the strong sense identified earlier, but they need not, if one's presuppositions act as necessary, and not sufficient, filters and controls. But more needs to be said.

All presuppositions, and especially those of any Christian enquirer, ought to be kept fresh and in trim by being kept under review. How is this feat performed? A Christian can hardly maintain a consistent Christian position without making reference to the foundational, constitutive documents of his faith. For after all it is in virtue of the authority of these documents that he is a Christian. So one essential way of keeping one's presuppositions fresh and in trim, it seems to me, and making good one's credentials as an authentic Christian scholar, is by allowing one's current findings, and the nature of the presuppositions that condition these findings, to feed back to the original documents. The original documents must be given the opportunity to check, qualify and reform one's presuppositions.

Not to do this, to block such feedback, is a virtual guarantee that one is beginning to conduct one's Christian enquiries in an a priori rationalistic fashion. It needs to be stressed that such rationalism is not the sole prerogative of the radical or liberal wing of the Christian church; there is a conservative rationalism as well. The only way of having a hope of successfully avoiding either kind of rationalism, or at least of minimising its influence, is to review one's presuppositions in the light of the primitive documents.

Such a review can never be carried out infallibly, for we are not infallible. It may be that we shall simply wear the glasses of our presuppositions whenever we consult the documents. And it may be that our enquiries are so theoretically dense that the primitive documents have little purchase on 
them. But it may be that we can genuinely call our presuppositions into question, though of course, as we have stressed, only in the light of other presuppositions we adopt, however temporarily. And we ought never to take for granted that our enquiries are so theoretical that the Bible has nothing to say about them. The only long-term hope of avoiding a nonChristian dogmatism is to travel around the feedback circuit as often as we can.

There is a second way in which Christian scholars can strive to keep their presuppositions fresh and wholesome. This is by reflecting not only on the foundation documents directly, but also by casting sideways glances at other scholars with different presuppositions. In some cases these presuppositions may be only slightly different from one's own, in other cases very different. But it may be that these presuppositions will turn out to be more authentically Christian than those one is currently operating with. It is surely good Christian practice to seek to discover whether or not this is so, and to modify one's presuppositions should this prove necessary.

It is in ways such as these that subjectivism and unchristian dogmatism (often two names for the same thing) can be avoided, and true objectivism cultivated.

It may be objected that the last thing that the Christian ought to want to be is objective. For when Christ calls a person into his service then, it might be said, he calls him to a life of commitment. And can commitment walk hand in hand with objectivity?2

Here I think that it is helpful to distinguish between objectivity and neutrality. They are frequently confused. Objectivity (at least as I am using the term here) is concerned with procedures, while neutrality is concerned with outcomes. Objectivity in Christian scholarship is crucial; the need to weigh evidence, to observe the appropriate investigative procedures, to distinguish what is relevant from what is irrelevant, to be self-critical about one's presuppositions, and in one's reasonings and conclusions-all these procedures are part of what is meant by being objective. The Christian has no stake in not being objective in this sense. Such procedures are quite

${ }^{2}$ For a discussion and defence of objectivity in various disciplines see Paul Helm (ed.), Objective Knowledge (London, IVP 1987). 
compatible with Christian presuppositions, and may even be required by them.

Using such procedures, together with what the enquirer regards as bona fide Christian presuppositions, may point unmistakably to one set of conclusions. It would be carrying objectivity too far for the Christian then to say that, in the interests of objectivity, he was going to suspend judgment on that matter to which the evidence unmistakably pointed. That would be to confuse objectivity with neutrality.

Consider, once again, our man in the dock. Using the most stringent procedures the evidence might point, let us say, to the man's innocence. He is, as far as any human procedure can establish the matter, objectively innocent. But it would then be absurd to say that a 'not guilty' verdict, because it came down on one side and not on the other, was not 'objective'. It is precisely because the investigative procedures were as objective as it was possible to make them that the court is warranted in not being neutral towards the accused, and acquitting him of the charge. 